\title{
Scleroderma and the Oral Health Implications
}

\author{
Hajer Abdulhafid Derbi* and Gelsomina L Borromeo \\ University of Melbourne, Australia
}

Submission: September 12, 2017; Published: January 22, 2018

*Corresponding author: Hajer Abdulhafid Derbi, University of Melbourne, Australia, Tel: 61 450314445; Email: hajer.derbi@unimelb.edu.au

\begin{abstract}
Patients with scleroderma present with a wide range of oral manifestations. This is due to the unique manifestations involving the oral soft tissues and resulting in restricted mouth opening, xerostomia, erosion of teeth, and periodontal disease. As a consequence, oral hygiene, providing dental treatment and fabrication of prosthetic appliances pose significant challenges primarily related to limited access and obliteration or shallowing of the mucobuccal folds. This paper presents the dental management and splint construction for a 41-year-old lady suffering from scleroderma.
\end{abstract}

Keywords: Scleroderma; CREST; Systemic sclerosis; Oral management; Limited mouth opening; Splint

Abbreviations: SSc: Systemic Sclerosis; CREST syndrome: Calcinosis, Raynaud's phenomenon, Oesophageal dysmotility, Sclerodactyly and Telangiectasia

\section{Introduction}

Scleroderma, or systemic sclerosis, is a chronic autoimmune disease characterized by inflammation, and vascular and fibrotic changes of the skin as well as internal organs [1-3]. This connective tissue disorder has been classified into two subsets: systemic scleroderma and localized sclerosis [4]. Localized scleroderma (sclerosis) is usually limited to skin lesions, and sometimes extends to involve the underlying muscle and bone. It is further subdivided into morphea, generalised, bullous, linear, and deep forms [4].

Systemic forms of scleroderma fall into the category of primary cutaneous sclerosis as designated by The American Academy of Dermatology. Systemic Sclerosis (SSc) can be further divided based on the extent of skin and internal organ involvement, into subcategories including diffuse SSc, which includes systemic scleroderma, and limited SSc, which includes CREST syndrome, involves calcinosis, Raynaud's phenomenon, oesophageal dysmotility, sclerodactyly, and telangiectasia.

Patients with diffuse systemic sclerosis have extensive skin indurations with the possibility of near total organ system involvement. Cutaneous sclerosis is identified by a rapid development of symmetric skin thickening of the proximal and distal extremities, face and trunk together with internal organ involvement. Damage to the heart, kidneys, and lungs affect the course of the disease. Patients with limited cutaneous SSc typically have skin sclerosis that is restricted to the hands, and sometimes the face and neck. Patients may also have prominent vascular manifestations and frequently exhibit features of CREST syndrome. The pathological process evolves through oedematous, indurative, and atrophic phases sequentially over time, and as such, subtle differences exist between patients affected by this disease. It occurs more commonly in women (estimated female to male ratio, 4:1), and the age of peak onset is 30 to 50 years [5].

Scleroderma is an uncommon autoimmune disease affecting connective tissues, with an approximate prevalence of 20/100 000 . It presents great challenges not only to the medical professionals but also the dental professionals with its profound impact on oral health. The current paper present dental management and splint construction for a 41 year old female, who was diagnosed with diffuse scleroderma.

\section{Case Presentation}

A 41-year-old female who was diagnosed in 2001 with Diffuse Scleroderma, Lichen sclerosis (vulva), minor Beta Thalassaemia, pulmonary interstitial fibrosis, and secondary Sjogren Syndrome was referred for ongoing oral health management by her general dentist to the Special Needs Clinic in 2014. Miss VK lived independently and had recently lost her job but was seeking further employment.

As a consequence of her condition, Miss VK was also suffering from depression managed with the Antidepressant Selective Serotonin and Norepinephrine Neuptake Inhibitor (SNRIs) desvenlafaxine $100 \mathrm{mg}$. She was also prescribed a calcium channel antagonist (felodipine 10mg daily) to manage her Raynaud's phenomena and sclerodactyly. She reported dry eyes that were reviewed six monthly by an ophthalmologist who had prescribed eye lubricant drops and ointment. In addition, Miss VK was taking 


\section{Advances in Dentistry \& Oral Health}

indomethacin $25 \mathrm{mg}$ for the management of right knee pain and esomeprazole $20 \mathrm{mg}$ for gastric reflux.

Miss VK had several dental appointments with private dental practitioners where the majority of her restorative treatment was performed. She also had all 3rd molar teeth removed under general anesthesia at a local private hospital. The general dentist referred her for ongoing management by a dental specialist as he struggled to perform oral care due to the limited mouth opening.

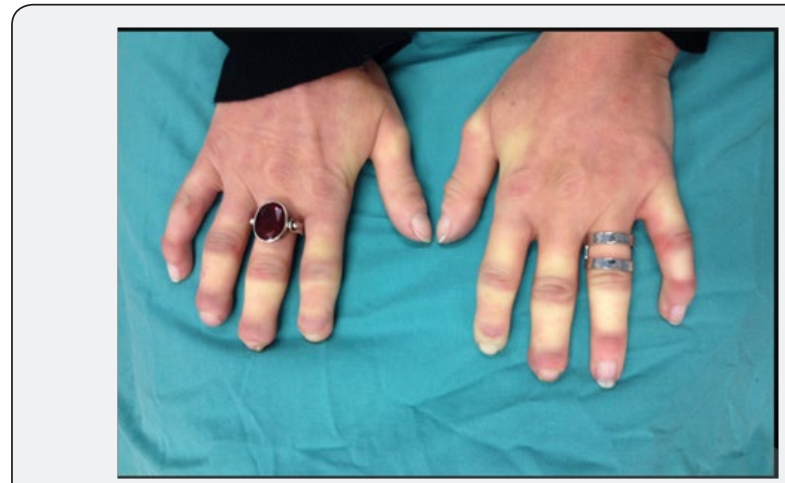

Figure 1a: The hands of Miss VK showing significant Raynaud's phenomenon.

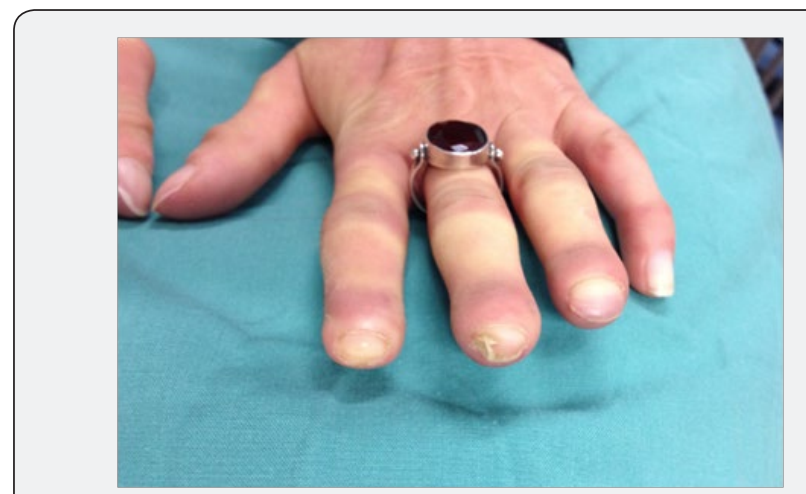

Figure 1b: Sclerodactyly: fibrosis of the skin of the finger associated with atrophy of fingertips.

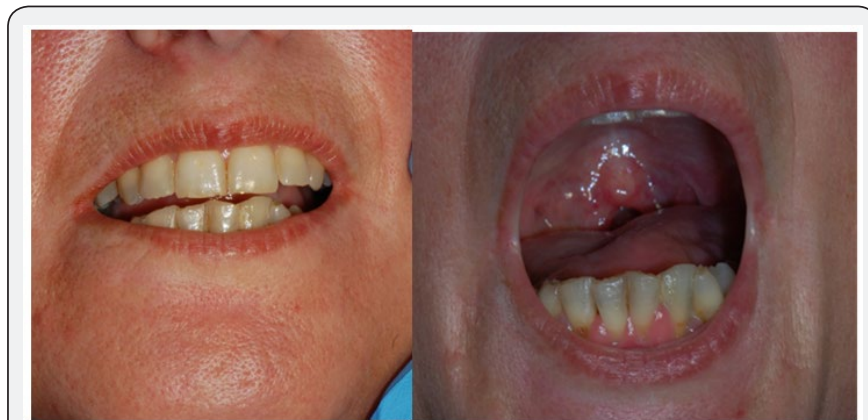

Figure 2: Severe trismus and microstomia with reduced interincisal distance $(21 \mathrm{~mm})$ resulting from dense perioral fibrosis. Note upward retraction and shortening of uvula from underlying scar tissue.

Miss VK presented with sclerodactyly with atrophy and ulceration of her digits (Figure 1), atrophy of the nasal ala creating a pinched nose appearance and severe microstomia. Her oral opening allowed $21 \mathrm{~mm}$ interincisal distance (Figure 2) with $35 \mathrm{~mm}$ intercommissural distance. In spite of these restrictions, she presented with good oral hygiene. She had a very dry mouth and heavily restored dentition, mild alveolar bone loss with grade one mobility localized to the lower anterior teeth, and gingival recession on the facial aspects of her mandibular anterior teeth, which was prominent in the 34 area where one-third of the root was exposed (Figure 3). The marginal gingiva also showed signs of inflammation where the skin tightness was pulling on the intra oral mucosa. In addition, thin tight mucosa was noticed bilaterally in the posterior buccal vestibule together with severe buccal mucosal fibrosis (Figure 4). Miss VK reported a history of bruxism and oesophageal reflux contributed to severe palatal attrition/ erosion of the upper anterior teeth (Figure 5).

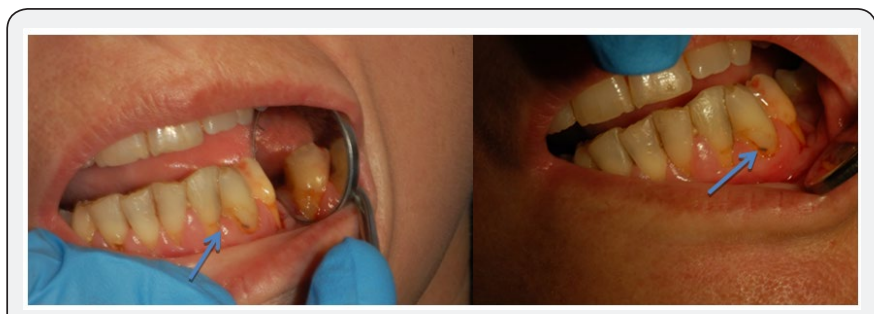

Figure 3: Gingival recession with no attached gingiva facial and distal to 34 in Miss VK who showed otherwise good oral hygiene.

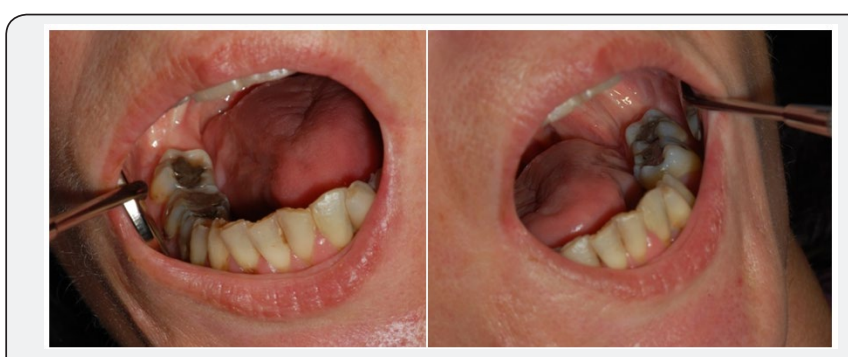

Figure 4: Thin tight mucosa in the posterior buccal vestibule.

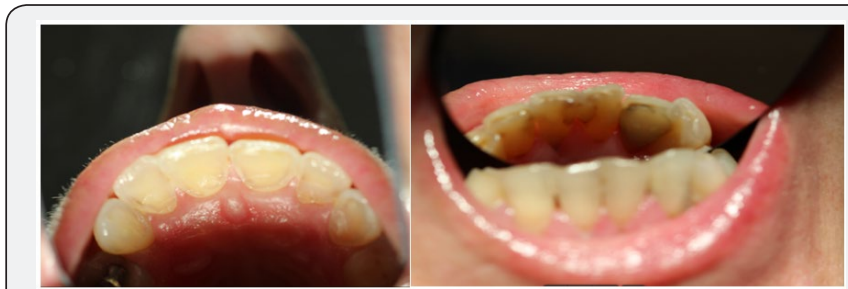

Figure 5: Erosion/attrition of palatal surface of upper teeth, heavily restored lower anterior teeth.

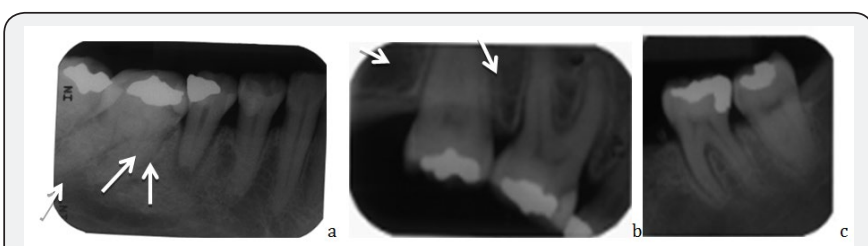

Figure 6:

a. Widening of the periodontal ligament space with a periapical lesion and external root resorption around 45

b. Widening of the periodontal ligament space around the roots 16 and 17 .

c. Signs of early widening of the periodontal ligament space around 37 and widening of the periodontal ligament space around the roots of 36 . 


\section{Advances in Dentistry \& Oral Health}

Limited intra-oral access was a significant impediment to dental treatment as noted by her previous general dentist, as well as limiting her ability to maintain oral hygiene. Several recurrent and new carious lesions were diagnosed clinically and by radiographic analysis. The latter revealed thickening and widening of the periodontal ligament or periodontal ligament space (Figure $6 \mathrm{~b} \& 6 \mathrm{c}$ ). In addition, a periapical lesion was noted associated with 45 ; however, the tooth was neither symptomatic nor tender to percussion (Figure 6a).

Multiple conservative restorations were completed; however, limited oral opening was a significant impediment to dental treatment. To overcome this, only one restoration was completed per visit with multiple rest breaks and use of low-volume suction with soft flexible head. Extraction of tooth 45 was performed by accessing the tooth from the lingual aspect using both luxators and pediatric forceps again with multiple rest breaks in between.

Progressive microstomia had made oral hygiene measures increasingly difficult to perform. Although the patient brushed her teeth twice a day using a manual toothbrush, and flossed nightly, she found flossing a challenging task. Limited manual dexterity, resulting from the sclerodactyly continued to hamper her oral hygiene efforts. Oral hygiene strategies included the use of an electric toothbrush and interdental brushes together with daily fluoride treatments.

Periodontal diseases can be a problem for patients with scleroderma. The gingival tissues themselves also sclerose and vascularity decreases, resulting in delayed healing. Gingival recession was treated by performing scaling and root debridement and providing chlorhexidine $0.5 \%$ gel to be used twice daily for 14 days followed by replacement with chlorhexidine $0.2 \%$ mouthwash to be used once daily.

Oesophageal dysmotility is the most prominent visceral manifestation of SS, predisposing individuals to Gastroesophageal Reflux Disease (GORD), which may be firstly diagnosed by a dental practitioner [6]. The resultant acidic environment within the oral cavity erodes enamel and dentin, which was evident in this case. Construction of an intraoral splint that could also be used as a fluoride carer allowed for management of both the erosion and tooth wear due to the bruxism. Splint construction was a significant challenge for Miss VK in light of limited oral access, facial and mucosal fibrosis and shallowing of the mucobuccal folds. Preliminary alginate impressions were taken using modified pediatric three-piece standard trays (Figure 7a). Three impressions were repeated in an attempt to improve extend and retention (Figure $7 \mathrm{~b}$ ). Three casts were trimmed and then combined into a single three-part cast, from which an impression was taken and a final cast was obtained. The patient was able to insert and remove the splint successfully on her own. At the 9-month follow-up visit the splint was still being used by Miss VK and comfort was not an issue (Figure 7).

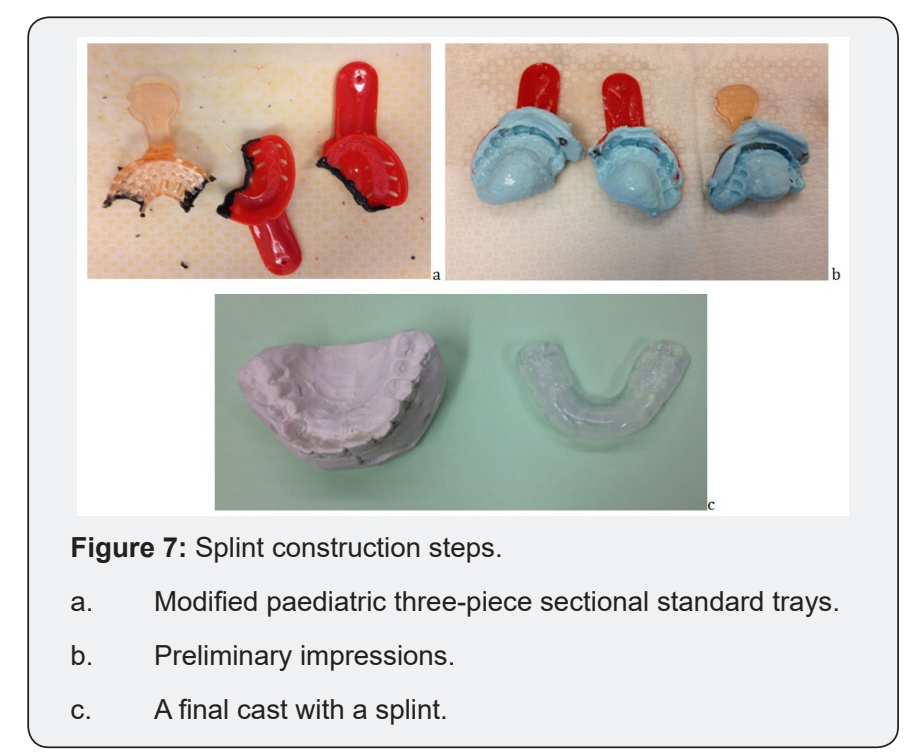

\section{Discussion}

Restricted mouth opening in systemic sclerosis, resulting from facial and mucosal fibrosis, may compromise oral access which limits mouth opening in 70\% of these patients [7] and prevents adequate self-care. Hand and joint function may decline over time mainly because of skin tightening, rather than arthropathy, which may have a negative impact on daily activities, including maintenance of adequate oral care. In conjunction with other changes such as xerostomia this will increase the caries risk of this cohort. These factors highlight the need for these patients to have regular dental follow-ups, with appropriate preventive measures [8-12].

Periodontal disease can also be a problem for patients with scleroderma. This is unlikely to be solely related to difficulty in performing oral hygiene. Microvasculopathy is a feature of systemic sclerosis [13], which has been reported in biopsy specimens of thickened periodontal ligament membranes. Reduced vascularity with resulting tissue ischemia may explain the increased susceptibility to periodontal disease, and thus the increased prevalence of loose or mobile teeth in these patients. Furthermore, collagen changes of the oral mucous membranes result in the thin, pale and tight appearance and loss of vascular integrity. This also contributes to gingival recession and stripping of the attached gingiva.

Patients with scleroderma exhibit decreased lacrimal and salivary secretion rates, which could be due to fibrosis of the glandular tissues or to secondary Sjogren's syndrome. Sicca syndrome in scleroderma is probably a complication of the fibrotic process around capillaries and excretory ducts [14], Capillary wall sclerosis could induce functional abnormalities by reducing vascular permeability, and periductal fibrosis that interferes with salivary excretion [15]. 
Survival rates for patients with scleroderma mainly depend on the subtype of the disease with pulmonary hypertension and scleroderma renal crisis important prognostic predictors. Limited cutaneous SS has a better prognosis with a 10 -year survival rate of $71 \%$ compared to diffuse cutaneous SS at $21 \%$.

\section{Conclusion}

Patients with scleroderma present with a wide range of oral manifestations. This is due to the unique manifestations involving the oral soft tissues and resulting in restricted mouth opening, xerostomia, erosion of teeth, and periodontal disease. Routine dental procedures may require creative modifications as occurred in the construction of an intraoral splint for this patient. Early intervention is important given the progressive sclerosis that occurs in many patients and hence dental management requires a multidisciplinary approach.

\section{References}

1. American Rheumatism Association Diagnostic and Therapeutic Criteria Committee (1980) Preliminary criteria for the classification of systemic sclerosis (scleroderma). Subcommittee for scleroderma criteria of the American Rheumatism Association Diagnostic and Therapeutic Criteria Committee. Arthritis Rheum 23(5): 581-90.

2. Australian Rheumatology Association (2016) Australian Scleroderma Interest Group (ASIG).

3. Albilia JB, Lam DK, Blanas N, Clokie CM, Sándor GK (2007) Small mouths... Big problems? A review of scleroderma and its oral health implications. J Can Dent Assoc 73(9): 831-836.

4. Fischer DJ, Patton LL (2000) Scleroderma: oral manifestations and treatment challenges. Spec care Dentist 20(6): 240-244.

This work is licensed under Creative Commons Attribution 4.0 Licens DOI: 10.19080/ADOH.2018.07.555716
5. Steen V, Medsger TA (1990) Epidemiology and natural history of systemic sclerosis. Rheum Dis Clin North Am 16(1): 1-10.

6. Barron RP, Carmichael RP, Marcon MA, Sandor G (2003) Dental erosion in gastroesophageal reflux disease. J Can Dent Assoc 69(2): 84-89.

7. Chaffee N (1998) CREST Syndrome: Clinical Manifestations and Dental Management. J Prosthodont 7(3): 155-160.

8. Neville BW, Damm DD, Allen CM, Bouquot JE (2002) Oral and maxillofacial pathology. 2nd ed. p 137, W.B. Saunders Co, ISBN 13: 9781416034353, Philadelphia, USA.

9. Eversole L, Jacobsen P, Stone CE (1984) Oral and Gingival Changes in Systemic Sclerosis (Scleroderma). J Periodontol 55(3): 175-178.

10. Wood RE, LEE, P (1988) Analysis of the oral manifestations of systemic sclerosis (scleroderma). Oral Surg Oral Med Oral Pathol 65(2): 172178.

11. Nagy G, Kovács, J, Zeher M, Czirják L (1994) Analysis of the oral manifestations of systemic sclerosis. Oral Surg Oral Med Oral Pathol 77(2): 141-146.

12. Norton WL, Nardo JM (1970) Vascular disease in progressive systemic sclerosis (scleroderma). Ann Intern Med 73(2): 317-324.

13. Janin A, Gosselin B, Gosset D, Hatron P, Sauvezie B (1988) Histological criteria of Sjogren's syndrome in scleroderma. Clin Exp Rheumatol $7(2): 167-169$.

14. Hebbar M, Janin A, Huglo D, Copin MC, Lafyatis R, et al. (1994) Xerostomia in Systemic Sclerosis: Systematic Evaluation by Salivary Scintigraphy and Lip Biopsy in Thirty-Four Patients. Arthritis Rheum 37: 439-441.

15. Trad S, Amoura Z, Beigelman C, Haroche J, Costedoat N, et al. (2006) Pulmonary arterial hypertension is a major mortality factor in diffuse systemic sclerosis, independent of interstitial lung disease. Arthritis Rheum 54(1): 184-191.

\section{Your next submission with Juniper Publishers will reach you the below assets}

- Quality Editorial service

- Swift Peer Review

- Reprints availability

- E-prints Service

- Manuscript Podcast for convenient understanding

- Global attainment for your research

- Manuscript accessibility in different formats

( Pdf, E-pub, Full Text, Audio)

- Unceasing customer service

Track the below URL for one-step submission https://juniperpublishers.com/online-submission.php 